\title{
Владимир ВАРНАВСКИЙ
}

\section{ЕС И РОССИЯ В ГЛОБАЛЬНЫХ ЦЕПОЧКАХ СОЗДАНИЯ СТОИМОСТИ}

\begin{abstract}
Аннотация. В статье анализируются процесс формирования глобальных цепочек создания стоимости (ГЦСС) и характеристика участия в них стран ЕС и России. Приведён обзор экономической литературы, теоретических основ и концепции ГЦСС. Даны количественные оценки участия стран ЕС и России в ГЦСС на основе имеющихся межстрановых межотраслевых балансов WIOD и базы данных международной торговли в категориях добавленной стоимости TiVA. Особое внимание уделено основным показателям ГЦСС, включая экспорт промежуточной продукции, добавленную стоимость в составе валового экспорта и "восходящее и нисходящее” участие в глобальных цепочках. Приведены авторские оценки места ЕС и России в ГЦСС. Показано, что вхождение стран ЕС в глобальные производственные цепочки можно считать близким к оптимальному.

Ключевые слова: ЕС, Россия, глобальные цепочки, промежуточная продукция, конечная продукция, добавленная стоимость, “восходящее” и “нисходящее” участие.
\end{abstract}

Глобальные цепочки создания стоимости (ГЦСС, Global Value Chains $\mathrm{GVCs})^{1}$ - это новый, появившийся в 2010-е годы инструмент исследования и количественной оценки одного из наиболее ярких проявлений экономической составляющей глобализации - транснационализации производства. Он активно разрабатывается за рубежом международными организациями и экономическими научными школами.

\footnotetext{
${ }^{1}$ В отечественной экономической литературе терминология в отношении ГЦСС только складывается. Встречаются и другие переводы на русский язык понятия GVCs, в частности, "глобальные цепочки стоимости", "глобальные цепочки добавленной стоимости", “глобальные производственно-сбытовые цепочки” и т.д. В данной статье используется термин, введённый в научный оборот в 2016 г. в документе ООН "Руководство по измерению глобального производства" [Руководство..., 2016].
}

(C) Варнавский Владимир Гаврилович - доктор экономических наук, профессор, заведующий сектором ИМЭМО РАН им. Е.М. Примакова. Адрес: 117997, Россия, Москва, ул. Профсоюзная, 23; ведущий научный сотрудник, Институт проблем управления РАН. Aдрес: 117997 Москва, ул. Профсоюзная, 65. $\boldsymbol{E}$ mail: varnavsky@imemo.ru

DOI: http://dx.doi.org/10.15211/soveurope1201992103 


\section{Основные тенденции}

Современное крупномасштабное производство в значительной степени строится вокруг глобальных цепочек движения товаров и услуг, когда промежуточная продукция (intermediate goods) в воспроизводственном процессе движения к конечному потребителю пересекает границы нескольких стран. По данным ЮНКТАД, промежуточная продукция составляет почти половину объёма мировой торговли товарами, и эта цифра остаётся достаточно стабильной в течение последних 20 лет [Trade ..., 2016: 118].

Формирование ГЦСС началось в период активной фазы глобализации в 1980-е годы. В подавляющем большинстве случаев цепочки создавались, контролировались, координировались транснациональными и многонациональными компаниями (ТНК и МНК) через сеть филиалов, подрядчиков, сбытовых компаний или посредством прямой купли-продажи товаров и услуг. Европейская комиссия отмечает: "Международное производство, управляемое многонациональными компаниями в стремлении к повышению эффективности, все чаще организуется в форме глобальных цепочек создания стоимости. Их появление бросило вызов традиционным представлениям о мировой торговле и потребовало от Европейского Союза соответствующим образом адаптировать свою политику в области торговли и развития, чтобы обеспечить эффективное решение всех взаимосвязанных вопросов в мировой экономике" [Global ..., 2017].

Однако постепенно ТНК и МНК все в большей степени сосредоточивались на ключевых для современного производства нематериальных, но стратегически важных направлениях деятельности и активах: развитие бизнеса, проведение, организация и общее руководство научными и прикладными исследованиями, дизайн, брэндинг, маркетинг. В результате они превратились в холдинги, обеспечивающие себе максимальную прибыль, а производственные, торговые, сбытовые операции, функции по гарантированию, обслуживанию, утилизации продукции были переданы ими специализированным компаниям.

Также со временем наметился и стал осуществляться отход ТНК и МНК от стратегии прямых иностранных инвестиций в направлении предпочтения косвенных форм контроля за производственными процессами путем аутсорсинга и привлечения независимых поставщиков. В отдельных сегментах производственного процесса происходил эволюционный переход от вертикальной интеграции к горизонтальной кооперации. В результате к настоящему времени сложились сложные, многоуровневые производственные отношения, цепи поставок промежуточной продукции как в системе холдингов, так и внешней по отношению к ним среде, глобальные цепочки создания стоимости, сетевые структуры, пронизывающие и связывающие по вертикали и горизонтали практически всю экономику. А ТНК и МНК за относительно короткий исторический срок (2-3 десятилетия) из преимущественно глобальных производителей превратились в распорядителей, координаторов и управляющих мировыми рынками.

Быстрому становлению и развитию ГЦСС способствовали не только производственные, но и институциональные факторы, в первую очередь: либерализация международной торговли и инвестиций, укрепление мер международнополитического доверия, расширение конкурентного пространства до глобальных 
размеров. Важнейшим институциональным фактором и катализатором ГЦСС стали информационно-коммуникационные технологии (ИКТ), которые произвели революцию как в производстве, так и в управлении. Они в значительной степени определяли основные направления научно-технического прогресса в производственных, сбытовых, транспортных, маркетинговых системах, воздействовали на развитие межстрановой производственной кооперации. ИКТ дали толчок аутсорсингу, логистике, сделали возможным реальное во времени управление международной производственной кооперацией. В результате возникла уникальная для мировой экономики ситуация, когда в производстве фактически исчезли ограничители и любой товар может быть выпущен и доставлен в любую точку планеты практически в неограниченном количестве, если в этом есть потребность.

Таким образом, глобализация и сопутствующие ей институциональные и технологические факторы привели к формированию по сути новой конфигурации мирового экономического пространства (производство, торговля, занятость) и международного разделения труда, в котором каждая страна и регион имеют определенное место в рамках концепции глобальных цепочек создания стоимости. Европейский Союз и Россия также заняли свои, особенные, во многом взаимодополняющие сегменты и ниши в мировом производстве и в глобальных производственно-сбытовых цепочках.

\section{Концепция}

В основе концепции глобальных цепочек лежат научные разработки по двум крупным направлениям экономической мысли последних десятилетий. Первое: выделение в мировом воспроизводственном процессе специфического сегмента трансграничного движения чистой (т.е. очищенной от повторного счета) стоимости и разработка методологии соответствующего анализа. Второе: построение межстрановых межотраслевых балансов (ММОБ).

В первом из направлений понятийный базис составили такие категории, как: "цепочка создания стоимости" (value chain) - введена в научный оборот М. Портером [Porter, 1985]; “глобальные продуктовые цепочки” (global commodity chains) проанализирована впервые Г. Джереффи и М. Корженевичем [Gereffi, 1994] и "вертикальная специализация" (vertical specialization) - предложена Д. Хаммелсом, Д. Рапопортом и К-М. Йи [Hummels, 1998]. Постепенно в экономический оборот вводились и другие понятия, характеризующие различные стороны глобализации производственной деятельности, в частности: фрагментация производства, международный аутсорсинг, торговля операциями, специализация стран по бизнесзадачам и бизнес-функциям, глобальные сети․․ В 2013 г. в одном из исследований ОЭСР были предложены еще два термина, широко используемые в настоящее время для получения количественных оценок участия страны в ГЦСС через экспорт так называемое "восходящее участие" (forward participation) и через импорт - "нисходящее участие" (backward participation) [Interconnected ... 2013: 12].

\footnotetext{
${ }^{1}$ CM., например, обзор исследований по этой теме: [Faße, 2009, Trade ..., 2012, De Backer, 2014, Measuring..., 2017].
}

Современная Европа, 2019, №1 
Появляющиеся новые категории, понятия и термины формировали, дополняли и расширяли представление о глобальных цепочках. Многие из них предполагали разработку методик, методов и формул расчёта соответствующих показателей.

В ходе работы в этом направлении необходимо было решать ряд методологических задач. Во-первых, чтобы получать корректные оценки ГЦСС надо было очистить экспорт и импорт от повторного счёта, т.к. статистика внешней торговли ведется по валовой стоимости, а показатели глобальных цепочек рассчитываются по чистой стоимости. Во-вторых, нужно было структурировать внешнеторговые потоки по функциональному назначению, т.е. разделить экспорт и импорт на чистую и промежуточную продукцию, которые по-разному входят в воспроизводственный процесс и, соответственно, в глобальные цепочки ${ }^{1}$. В ходе решения этих задач постепенно сформировалась новая предметная область исследований ГЦСС под названием “торговля в категориях добавленной стоимости” (Trade in Value Added, TiVA) $)^{2}$.

В 2010 г. американские экономисты Р. Купман, У. Пауэрс, Ч. Ванг и Ш.-Ч. Вэй предложили подход к разложению экспорта на составляющие компоненты в зависимости от их места в воспроизводственном процессе страны-импортера и соответствующую методику расчетов [Koopman, 2010]. В дальнейшем эта методика была положена в основу совместной инициативы ОЭСР и ВТО по разработке базы данных TiVA, которая в настоящее время наряду с построенными межстрановыми межотраслевыми балансами выступает основным методическим и фактографическим фундаментом анализа ГЦСС в мировой экономике [Trade ..., 2012: 20]. Eе последняя версия 2016 г. позволяет провести анализ показателей, характеризующих международную торговлю в категориях добавленной стоимости и степень участия в глобальных цепочках для 64 стран мира (в том числе и России) в разрезе 34 отраслей производства и услуг. Общее число экономических показателей базы данных - 40, в том числе: 13 - по добавленной стоимости в составе экспорта и импорта, а также 2 показателя участия страны в "восходящих" и "нисходящих" цепочках ${ }^{3}$. Динамические ряды составлены за период с 1995 по 2011 годы.

Другим важным направлением работ при формировании концепции ГЦСС стала разработка ММОБ, аналогичных широко известным и апробированным на практике национальным межотраслевым балансам (МОБ). Без замыкания экспортноимпортных потоков на полный воспроизводственный цикл через таблицы “затраты - выпуск” невозможно было получить достаточно точные оценки участия стран и отраслей в мировой экономике.

В теоретическом плане особых проблем на пути доработки национальных межотраслевых балансов в части выделения специальных блоков экспортно-импортных поставок не возникало - разница между экспортом и импортом выделяемых в МОБ

${ }^{1}$ Одни из первых работ по этой тематике: [Bergstrand, 2008, Daudin, 2009, Miroudot, 2009].

${ }^{2}$ Используемые в отечественной экономической литературе дословные переводы этого термина как “торговля добавленной стоимостью” или “торговля по добавленной стоимости”, с нашей точки зрения, не корректны, торговать стоимостью нельзя - торгуют товарами и услугами по цене, которая складывается на рынке. В данной статье используется термин из рекомендаций ООН [Руководство..., 2016].

${ }^{3}$ Перечень показателей см.: [TiVA..., 2017]. 
отраслей входит в расчет конечного потребления. Но перенесение моделей МОБ с национального на глобальный уровень сталкивалось с рядом статистических и расчетных проблем. Во-первых, размерность таких балансов для мировой экономики вырастает на порядки и достигает несколько тысяч строк и столбцов. Во-вторых, для составления ММОБ необходима полученная по единой методике отраслевая статистика потоков товаров и услуг во внутреннем и трансграничном направлениях для всех стран. В-третьих, для каждой страны импорт и экспорт разделяются на конечное и промежуточное потребление в разрезе принятой в ММОБ отраслевой классификации.

В 2000-е годы были созданы, поддерживаются и могут быть использованы в целях анализа ГЦСС три основные базы данных ММОБ:

1) Inter-Country Input-Output (ICIO) [OECD..., 2015]. Разработана ОЭСР. Включает 63 страны (35 стран ОЭСР + 28 стран, не входящих в ОЭСР, в том числе Россия) + одна условная страна под названием “Остальной мир” (для балансировки и выхода на данные по всей мировой экономике). 34 отрасли. Годы: 1995-2011.

2) Global Trade Analysis Project database (GTAP) [GTAP..., 2017]. Разработана и поддерживается Центром глобального анализа торговли Университета Пердью (США). 140 стран и регионов, вкл. Россию. 57 товарных групп. Годы: 2004, 2007 и 2011.

3) World Input-Output Database (WIOD) [World ..., 2016]. Разработана по заказу Европейской Комиссии (ЕК) консорциумом из одиннадцати европейских университетов и исследовательских центров, финансируется ЕК при поддержке отдельных стран. 43 страны (28 стран ЕС + 15 стран, не входящих в ЕС, вкл. Россию) + “остальной мир”. 56 отраслей. Годы: 2000-2014.

Таким образом, к настоящему времени разработаны и методология, и фактографическая основа углубленных исследований глобальных цепочек в страновом и отраслевом аспектах.

\section{Участие в ГЦСС}

Несмотря на экономические кризисы и разногласия по ряду внешнеполитических вопросов, что негативно отражается на торгово-экономическом сотрудничестве, ЕС и Россия остаются друг для друга важнейшими внешнеторговыми партнёрами. Наша страна для ЕС - четвёртый партнёр по объёму внешней торговли [Кеу..., 2017: 95], а ЕС для России - первый (таблица 1). В Европейский Союз идёт почти половина российского экспорта, и около $40 \%$ импорта поступает в Россию из $\mathrm{EC}^{1}$.

Экспорт может играть двоякую роль в воспроизводственном процессе страныимпортёра. Согласно концепции ГЦСС, стоимость импорта разбивается на две составляющие: стоимость продукции конечного и промежуточного потребления. Конечный продукт используется в стране-импортере полностью, а промежуточная продукция в результате переработки может: а) поступать в конечное потребление в ней же, б) быть реэкспортированной в страну происхождения ввезенной продукции (реэкспорт), в) вывозиться в третьи страны, т.е. войти в состав следующего звена производственной цепочки либо в конечное потребление за рубежом.

${ }^{1}$ Подробнее см., например: [Гладков, 2016]. Современная Европа, 2019, №1 
Основные внешнеторговые партнёры России, 2016 г.

Таблица 1.

\begin{tabular}{|l|l|c|c|c|l|c|c|}
\hline \multicolumn{3}{|c|}{ По импорту } & \multicolumn{4}{c|}{ По экспорту } \\
\hline Импортёры & $\begin{array}{c}\text { Объём, } \\
\text { млрд } \\
\text { евро }\end{array}$ & $\begin{array}{c}\text { Доля в общем } \\
\text { объёме } \\
\text { импорта, } \%\end{array}$ & Экспортёры & $\begin{array}{c}\text { Объём, } \\
\text { млрд } \\
\text { евро }\end{array}$ & $\begin{array}{c}\text { Доля в общем } \\
\text { объёме } \\
\text { экпорта, \% }\end{array}$ \\
\hline 1 & Все страны & 164,7 & 100 & & Все страны & 258,0 & 100 \\
\hline 2 & Китай & 34,4 & 20,9 & 2 & Китай & 25,3 & 4,7 \\
\hline 3 & США & 10,0 & 6,1 & 3 & Беларусь & 12,7 & 4,9 \\
\hline 4 & Беларусь & 8,6 & 5,2 & 4 & Турция & 12,4 & 4,8 \\
\hline 5 & Япония & 6,0 & 3,7 & 5 & Респ. Корея & 9,1 & 3,5 \\
\hline
\end{tabular}

Источник: [European..., 2017: 8].

Промежуточная продукция имеет основополагающее значение в формировании ГЦСС. Чем выше в экспорте доля продукции промежуточного потребления, тем существеннее потенциал включения страны в трансграничные производственные отношения. Конечно, многое зависит от структуры самой промежуточной продукции, но страны, имеющие высокие объёмы её поставок при определённых условиях, в том числе и за счёт поддержки государства, имеют бо́льшие возможности наращивания своего присутствия в глобальных цепочках по сравнению со странами, имеющими сравнительно низкий объём экспорта такой продукции.

Приближенно мера участия страны в глобальных производственных цепочках может быть оценена как отношение стоимости промежуточной продукции к экспорту. Такой подход используется, в частности, Европейским центральным банком (ЕЦБ) [Understanding..., 2016: 27]. Соответствующий показатель можно трактовать, как “индекс производственного участия”.

При среднем значении доли промежуточной продукции в мировом экспорте около $50 \%{ }^{1}$ ведущие страны имеют более высокие показатели индекса производственного участия в экономике других стран (таблица 2).

В общем объёме экспорта у России самый большой в мире индекс производственного участия в экономике других стран (более 90\%). С одной стороны, это плохо: получается, что для России характерна наиболее высокая в мире относительная зависимость от внешних рынков и состояния зарубежных экономик. Но с другой стороны, хорошо, поскольку только промежуточная продукция создаёт материальные предпосылки для укрепления места России в мировом промышленном производстве в случае продвижения в более высокие звенья ГЦСС.

${ }^{1}$ Существуют разные количественные оценки этого показателя. Так, ЮНКТАД считает его равным 46\% [Trade ..., 2016: 118], а ЕЦБ - примерно 60\%: [Economic, 2017: 75]. В среднем получается около $50 \%$.

Современная Европа, 2019, №1 


\begin{tabular}{|c|c|c|c|c|}
\hline \multirow{4}{*}{ Страна } & $\begin{array}{l}\text { T коне } \\
\text { ным }\end{array}$ & $\begin{array}{l}\text { i и промежул } \\
\text { гранового м }\end{array}$ & $\begin{array}{l}\text { ной продукции о } \\
\text { отраслевого бала }\end{array}$ & $\begin{array}{l}\text { Таблица } 2 . \\
\text { овных стран мира, } \\
\text { a WIOD за } 2014 \text { г.) } \\
\end{array}$ \\
\hline & \multirow{3}{*}{ всего } & \multicolumn{2}{|c|}{ Экспорт, млрд долл. США } & \multirow{3}{*}{$\begin{array}{c}\text { Индекс производственного } \\
\text { участия, \% }\end{array}$} \\
\hline & & \multicolumn{2}{|c|}{ в том числе: } & \\
\hline & & $\begin{array}{c}\text { конечной } \\
\text { продукции }\end{array}$ & $\begin{array}{c}\text { промежуточной } \\
\text { продукции }\end{array}$ & \\
\hline США & 1927 & 666 & 1261 & 65,4 \\
\hline Китай & 2425 & 1213 & 1212 & 50,0 \\
\hline Германия & 1683 & 718 & 965 & 57,3 \\
\hline Франция & 759 & 318 & 441 & 58,1 \\
\hline Италия & 589 & 264 & 325 & 55,2 \\
\hline Норвегия & 188 & 29 & 159 & 84,6 \\
\hline Канада & 564 & 172 & 392 & 69,5 \\
\hline Австралия & 288 & 45 & 243 & 84,4 \\
\hline Россия & 494 & 44 & 450 & 91,1 \\
\hline
\end{tabular}

Источник: рассчитано по WIOD 2014: [World ..., 2016].

К основным странам ЕС, получающим из России промежуточную продукцию относятся: Германия (в 2014 г. стоимость ввезенной российской продукции производственного назначения составила 26,4 млрд долл. США), Польша (19,7 млрд долл. США), Италия (12,6 млрд долл. США) ${ }^{1}$.

Как показывают наши расчёты по межотраслевым балансам WIOD, процесс продвижения России в глобальных цепочках на более высокие позиции начался еще до мирового финансово-экономического кризиса 2008-2009 гг. Так, в 20072014 гг. экспорт промежуточной продукции ряда отраслей обрабатывающей промышленности увеличился в несколько раз, особенно в отраслях по производству пищевых продуктов, кокса и в нефтепереработке (таблица 3).

Отсутствие балансов WIOD за более поздние годы не позволяет провести детальный анализ диверсификации производственного экспорта России после 2014 г., но надо полагать, что действие национальной программы импортозамещения может ускорить восхождение страны вверх по глобальным цепочкам.

На примере стран ЕС хорошо видно, что глобальные цепочки более чувствительны к изменению мировой конъюнктуры, чем товарный экспорт в целом. Так, во время экономического кризиса 2009 г. абсолютное падение экспорта промежуточных товаров всех ведущих стран ЕС было более сильным в сравнении с экспортом в це-

\footnotetext{
${ }^{1}$ Рассчитано по: WIOD 2014: [World..., 2016]. Современная Европа, 2019, №1
} 
лом. Например, в Германии экспорт в 2009 г. по сравнению с 2008 г. сократился на $22,6 \%$, а вывоз промежуточной продукции - на 25,9\%. Аналогичные показатели для других стран составили: Франция - 21,3\% и $24,5 \%$; Италия - $25,0 \%$ и $26,6 \%$; Испания $-19,2$ и 23,9\% [World ..., 2017: Table A58, Table A65].

Таблица 3.

Экспорт отраслей обрабатывающей промышленности России, поступающий в производственное потребление за рубежом

\begin{tabular}{|l|c|c|c|}
\hline \multirow{2}{*}{\multicolumn{1}{|c|}{ Отрасли по производству }} & \multicolumn{2}{|c|}{ Млн долл. США } & \multirow{2}{*}{$\begin{array}{c}\text { Рост 2007-2014 гг., } \\
\text { число раз }\end{array}$} \\
\cline { 2 - 3 } & 2007 г. & 2014 г. & \\
\hline Пищевых продуктов & 205 & 1215 & 5,9 \\
\hline Кокса и продуктов нефтепереработки & 14330 & 35388 & 2,5 \\
\hline Бумаги и бумажной продукции & 3538 & 8179 & 2,3 \\
\hline Продукции химической промышленности & 10736 & 18699 & 1,7 \\
\hline Компьютеров, электроники и оптики & 616 & 1115 & 1,8 \\
\hline Резиновых и пластмассовых изделий & 449 & 798 & 1,8 \\
\hline
\end{tabular}

Источник: рассчитано по: WIOD 2007, 2014: [World ..., 2016].

Проведённый анализ позволяет сделать ряд выводов. Во-первых, в показателях как валовой внешней торговли, так и глобальных цепочек период после кризиса 2008-2009 гг. был весьма сложным для ведущих стран ЕС. На смену кратковременному оживлению внешнеторговой деятельности приходили резкие и глубокие спады. Вся ведущая четверка в 2015 г. ещё не достигла уровня 2008 г. по экспорту товаров на внешний рынок и по поставкам продукции в рамках глобальных цепочек.

Во-вторых, динамика стоимости экспортируемой промежуточной продукции в своей основной тенденции повторяет кривую изменения стоимости экспорта. Но при этом по всем ведущим странам ЕС волатильность первого показателя неизменно выше, чем второго - в периоды кризисов вывоз промежуточных товаров сокращался сильнее, а во время подъёма возрастал более высокими темпами. Это связано, с нашей точки зрения, действием двух основных факторов.

Первый. Риски поставок в рамках глобальных цепочек, по-видимому, выше в сравнении с контрактами на закупку продукции по каналам внешней торговли. По этой причине процессы международной фрагментации производства и вертикальной специализации уже несколько лет идут по нисходящей траектории, а мировой объём аутсорсинга вернулся к уровню начала 2000 -х годов, резко сократившись с 105 млрд долл. США в 2014 г. до 77 млрд долл. США в 2016 г. [Constantinescu, 2017: 13, Timmer, 2016: 30, Global ..., 2018].

Bmорой. Повышенные риски глобальных цепочек связаны также с тем, что спрос на промежуточные товары определяется не только страной-импортером, но и третьими странами в рамках ГЦСС, а снижение потребления в стране-импортёре усугубляется дополнительным сокращением спроса в странах, стоящих выше неё в 
цепочках добавленной стоимости. В результате в перемещении промежуточной продукции между странами негативные тенденции усугубляются, сужение спроса за рубежом переносится на национальную экономику через механизм глобальных цепочек.

Кроме индекса производственного участия существуют и другие показатели оценки степени интеграции страны в международные производственные сети. В современной литературе в основе расчёта таких показателей лежат ММОБ, позволяющие получить количественные оценки с учетом прямых и косвенных экспортно-импортных потоков.

Выше отмечалось, что каждая страна входит в международные цепочки поставок по двум каналам - через экспорт (“восходящее участие”) и импорт (“нисходящее участие") промежуточной продукции. Коэффициент участия любой страны в восходящих цепочках определяется как отношение национальной добавленной стоимости в составе экспорта других стран к общему валовому объёму вывозимой ею на внешний рынок продукции. Другими словами, это та часть чистой стоимости, созданной в стране, которая входит в экспорт всех остальных стран. Коэффициент участия страны в нисходящих цепочках рассчитывается как доля иностранной добавленной стоимости в её экспорте.

В отечественной экономической литературе оба этих показателя весьма политизированы, хотя особых оснований к этому нет. Так, например, первый из них отражает лишь долю чистой стоимости в экспорте, которая после переработки в странеимпортёре вывозится в третьи страны. А второй показатель даёт представление о структуре импорта страны в плане его разделения на продукцию производственного и конечного потребления.

Анализ данных TiVA по участию EC, России и других стран в восходящих и нисходящих ГЦСС показывает, что глубоких различий в коэффициентах участия между странами мира нет. Так, индекс восходящего участия в ГЦСС отдельных стран составлял в 2011 г.: Германия - 24,1; Франция - 21,9; Норвегия - 40,5; Канада - 29,7; Австралия - 29,5; США - 24,9; Россия - 38,1. По нисходящему участию: Германия - 25,5; Франция - 25,0; Норвегия - 17,2; Канада - 23,4; Австралия - 14,1; США - 15,0; Россия - 13,7 [Trade ..., 2011].

Так, ведущие страны ЕС имеют практически одинаковую структуру участия в ГЦСС. В каждой из них примерно 20-25\% чистой стоимости, как вывозимой на внешний рынок, так и поступающей из-за рубежа, реализуется в составе глобальных цепочек. Это характерно и для других стран, входящих в мировое разделение труда преимущественно через торговлю продукцией обрабатывающей промышленности (например, США).

Несколько иная картина складывается в странах, значительную часть экспорта которых составляет продукция отраслей добывающей промышленности: России, Норвегии, Австралии, Канаде. Так как вывозимое ими за рубеж минеральное сырье и энергоресурсы проходят ещё много стадий обработки, прежде чем поступят в конечное потребление, их участие в восходящих цепочках значительно (в два раза) выше по сравнению со странами, торгующими в основном продукцией обрабатывающей промышленности.

В России широко распространено мнение о том, что высокая степень участия страны в международных производственных связях через экспорт товаров промежуточного потребления низких звеньев ГЦСС (добывающей промышленности и

Современная Европа, 2019, №1 
первичной переработки сырья) пагубно сказывается на её экономике, препятствует всестороннему развитию, консервирует сравнительно отсталую структуру хозяйства, ослабляет стимулы к инновациям. С нашей точки зрения, такие заключения являются односторонними, не учитывают и не отражают многих аспектов сложившейся к настоящему времени сложной картины разделения труда в современном мире и в этом плане не совсем корректны.

Во-первых, многие, в том числе и некоторые крупные развитые страны (Австралия, Канада) имеют сопоставимую с Россией, а Норвегия даже более высокую степень участия в восходящих цепочках за счёт добывающих отраслей. И это не рассматривается ими как существенный перекос в структуре экономики.

Во-вторых, сам по себе индекс восходящего или нисходящего участия в ГЦСС мало что говорит. Дело не в количественных показателях, а в качестве того процесса мирового разделения труда, который происходил последние 30 лет. И Россия заняла в нем, с нашей точки зрения, прочное и достойное место. Все могло быть гораздо хуже, если бы произошла пролонгация тенденций развития страны по трендам 1990-х годов. Сейчас же Россия не только обладает ресурсами, которые востребованы мировой экономикой, но и за счёт своего участия в нижних звеньях ГЦСС смогла произвести перевооружение отечественного промышленного производства и управления, сферы услуг и домашнего хозяйства на основе новейших технологий. Финансовую базу технического и технологического развития нашей страны в 2000-е годы обеспечили именно экспортно-ориентированные базовые отрасли добывающей промышленности.

В-третьих, перестроение конфигурации мирового геоэкономического пространства - дело очень сложное, которое не под силу одной отдельно взятой стране. Успешное по всему спектру отраслей и видов деятельности развитие любой национальной экономики в условиях глобализации и при достигнутом уровне развития производительных сил просто невозможно. Для этого ей необходимо иметь в распоряжении все виды материальных ресурсов и нематериальных активов, чего нет ни у одной из стран. В таких условиях завоевание новых сегментов и ниш на внешнем рынке происходит только за счёт сильных, конкурентоспособных компаний, а таковыми в России являются пока лишь предприятия добывающих и базовых отраслей тяжелой промышленности.

В-четвёртых, в категориях добавленной стоимости, которыми оперирует концепция ГЦСС, как раз восходящие цепочки дают максимальную прибыль участвующим в них компаниям и странам. Отрасли по добыче нефти и газа, минерального сырья и полезных ископаемых во всех странах мира, в том числе и в России, являются стабильно и высоко доходными, а прибыль выступает важной составной частью добавленной стоимости и государственных бюджетов.

\section{Bыводbl}

Глобальные цепочки создания стоимости могут стать одним из важных показателей экономической составляющей глобализации. Но пока статистической информации по ним недостаточно. Нужны длинные ряды и корректные расчёты, чтобы получать адекватное реальности представление о долгосрочных тенденциях и трендах глобальных цепочек. 
Основываясь на проведённом анализе для основных стран ЕС и принимая во внимание, что США имеют аналогичные этим странам индексы участия в восходящих цепочках, представляется, что для современной развитой экономики оптимальный уровень производственной кооперации в рамках ГЦСС находится в пределах 20-25\%. Для стран с ресурсной экономикой он выше и составляет 30-40\%.

Участие в глобальных производственных цепочках - это не панацея от всех “болезней” России, а всего лишь один из инструментов приобщения к передовым зарубежным производственным технологиям, практикам и бизнес-моделям, причём ограниченного действия и с пока недостаточно изученными долгосрочными последствиями.

Минеральные и сырьевые ресурсы - богатство России, шанс и “окно потенциальных возможностей” для её будущего развития, в том числе и через механизм ГЦСС. России важно не драматизировать доминанту своего участия в нижних звеньях восходящих цепочек, а заниматься системной работой, в первую очередь на европейском геоэкономическом направлении вместе с расположенными на нём странами по оптимизации производственных цепочек в интересах всех их участников.

Список литературы

Гладков И.С. (2016) Европейский Союз в системе современной международной торговли, Современная Европа, №1, с. 85-94.

Руководство по измерению глобального производства (2016) ООН, Нью-Йорк и Женева.

\section{References}

Bergstrand J. H. and Egger P. (2008) "The Growth of FDI Relative to Trade: Measurement, Determinants, and Consequences of International Trade Flows in Intermediates, University of Notre Dame", available at: http://www.jhubc.it/FULLEVENTCAL/UPLOADFILE2/Bergstrand\%20Paper.pdf.

Constantinescu C., Matto A. and Ruta M. (2017) “Trade Developments in 2016: Policy Uncertainty Weighs on World Trade, World Bank", available at:

http://documents.worldbank.org/curated/en/228941487594148537/pdf/112930-v1-revised-PUBLIC-1706109Global-Trade-Watch-Report-Web.pdf.

Daudin G., Rifflart C. and Schweisguth D. (2009) "Who Produces for Whom in the World Economy? Document de travail. OFCE N 2009-18", available at: https://www.ofce.sciences-po.fr/pdf/dtravail/WP200918.pdf.

De Backer K. and Miroudot S. (2014) "Mapping Global Value Chains, ECB, Working Paper Series, № 1677", available at: http://www.ecb.europa.eu/pub/pdf/scpwps/ecbwp1677.pdf.

Economic Bulletin (2017) "ECB, Issue 8/2017", available at:

http://www.ecb.europa.eu/pub/pdf/ecbu/eb201708.en.pdf?9bf4b347036beba6a70f79d1271a2496.

European Commission (2017) "European Union: Trade in goods with Russia", available at:

http://trade.ec.europa.eu/doclib/docs/2006/september/tradoc_113440.pdf.

European Commission (2017) "Global value chains", available at:

https://ec.europa.eu/europeaid/sectors/economic-growth/trade/global-value-chains_en.

Eurostat (2017) "Key Figures on Europe", available at:

http://ec.europa.eu/eurostat/documents/3217494/8309812/KS-EI-17-001-EN-N.pdf/b7df53f5-4faf-48a6-aca1c650d40c9239.

Faße A., Grote U. and Winter E. (2009) "Value chain analysis methodologies in the context of environment and trade research, School of Economics and Management of the Hanover Leibniz University, Discussion papers, no. 429", available at: https://www.econstor.eu/bitstream/10419/37104/1/609241915.pdf.

Gereffi G. and Korzeniewicz M. (1994) "Commodity Chains and Global Capitalism, Praeger, Westport, Connecticut (USA)", available at: https://www.questia.com/library/2963265/commodity-chains-and-globalcapitalism.

Gladkov I.S. (2016) Evronejskij Soyuz v sisteme sovremennoj mezhdunarodnoj torgovli, Sovremennaya Evropa, no. 1, pp. 85-94.

GTAP (2017) "Global Trade Analysis Project, Current GTAP Model”, available at: https://www.gtap.agecon.purdue.edu/models/current.asp.

Современная Европа, 2019, №1 
Hummels D., Rapoport D. and Yi K.-M. (1998) Vertical Specialization and the Changing Nature of World Trade, Economic Policy Review, June 1998, no. 2, pp. 79-99.

Koopman R., Powers W., Wang Z. and Wei S.-J. (2010) "Give Credit Where Credit Is Due: Tracing Value Added in Global Production Chains. Cambridge. NBER Working Paper, no. 16426", available at: http://www.nber.org/papers/w16426.pdf.

Miroudot S., Lanz R. and Ragoussis A. (2009) "Trade in intermediate goods and services, OECD Trade

Policy Working Paper, no. 93", available at: http://www.oecd.org/trade/its/44056524.pdf.

OECD (2013) "Interconnected Economies: Benefiting from Global Value Chains, OECD, Paris", available at: http://www.oecd.org/sti/ind/interconnected-economies-gvcs-synthesis.pdf Файл ОЭСР 2013.

OECD (2015) "Inter-Country Input-Output. (ICIO) Tables", available at:

http://www.oecd.org/sti/ind/input-outputtablesedition2015accesstodata.htm.

OECD (2017) "TiVA 2016 indicators - definitions, Version 1.1", available at:

http://www.oecd.org/sti/ind/tiva/TIVASaM_2016_Indicator_Definitions.pdf.

OECD and WTO (2012) "Trade in Value-Added: Concepts, Methodologies and Challenges (Joint

OECD-WTO) Note", available at: http://www.oecd.org/sti/ind/49894138.pdf.

Porter M.E. (1985) Competitive Advantage: Creating and Sustaining Superior Performance, The Free

Press, New York, NY, Collier Macmillan, London, UK.

Rukovodstvo po izmereniyu global'nogo proizvodstva (2016) OON, N'yu-Jork i Zheneva. [Guide to

Measuring Global Production], UN, New York and Geneva.

Statista (2018) "Global market size of outsourced services from 2000 to 2016", available at:

https://www.statista.com/statistics/189788/global-outsourcing-market-size/.

Timmer M.P., Los B., Stehrer R. and de Vries G.J. (2016) "An Anatomy of the Global Trade Slowdown based on the WIOD 2016 Release. University of Groningen, GGDC Research Memorandum, Number 162", available at: http://www.ggdc.net/publications/memorandum/gd162.pdf.

UNCTAD (2016) "Trade and Development Report: Structural Transformation for Inclusive and Sustained Growth, New York and Geneva, UNCTAD", available at:

http://unctad.org/en/PublicationsLibrary/tdr2016_en.pdf.

Understanding the Weakness in Global Trade: What Is the New Normal? (2016) "ECB, Occasional Pa-

per Series, no. 178", available at: http://www.ecb.europa.eu/pub/pdf/scpops/ecbop178.en.pdf.

World Bank (2017) "Measuring and Analyzing the Impact of GVCs on Economic Development", available at: https://www.wto.org/english/res_e/booksp_e/gvcs_report_2017.pdf.

(2016) "World Input-Output Database", available at: http://www.wiod.org/database/wiots16.

WTO (2017) "World Trade Statistical Review - Statistical Tables", available at: https://www.wto.org/english/res_e/statis_e/wts2017_e/wts2017_e.pdf.

WTO (2011) "Trade in Value-added and Global Value Chains: Statistical Profiles", available at: https://www.wto.org/english/res_e/statis_e/miwi_e/countryprofiles_e.htm.

\section{The EU and Russia in Global Value Chains}

Author: Varnavskii V., Doctor of Sciences (Economics), Professor, Primakov Institute of World Economy and International Relations, Russian Academy of Sciences (IMEMO). Address: 23, Profsoyuznaya Str., Moscow, 117997, Russia. Institute of Control Sciences, Russian Academy of Sciences. Address: 65, Profsoyuznaya Str., Moscow, 117997, Russia. E-mail: varnavsky@imemo.ru

Abstract. The article considers the formation of Global Value Chains (GVCs) and quantify the participation of major countries of the European Union and Russia in GVCs. It provides an overview of the economic literature and development of theoretical frameworks and concepts. A quantitative assessment of participation in GVCs for EU countries and Russia based on available data in the World Input-Output Database (WIOD) and Trade in Value Added (TiVA) is discussed. Special attention is given to the key GVCs indicators, including the export of intermediate goods, domestic value added embodied in gross exports and the "forward" and "backward" participation indexes. The author gives his vision of a place of the EU and Russia in GVCs. It is demonstrated that the EU's participation in GVCs can be defined as optimal.

Key words: EU, Russia, Global Value Chains (GVCs), intermediate goods, final consumption, value added, forward participation, backward participation.

DOI: http://dx.doi.org/10.15211/soveurope1201992103 